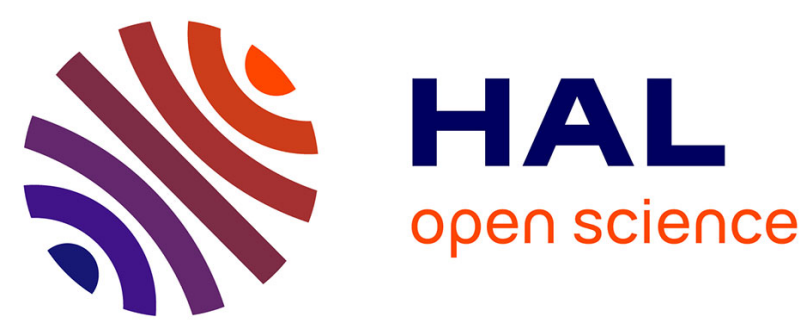

\title{
Challenging pollution and the balance problem from rare earth extraction: how recycling and environmental taxation matter
}

\author{
Bocar Samba Ba, Pascale Combes Motel, Sonia Schwartz
}

\section{To cite this version:}

Bocar Samba Ba, Pascale Combes Motel, Sonia Schwartz. Challenging pollution and the balance problem from rare earth extraction: how recycling and environmental taxation matter. Environment and Development Economics, 2020, 25 (6), pp.634-656. 10.1017/S1355770X20000054 . hal-03093684

\section{HAL Id: hal-03093684 \\ https://hal.science/hal-03093684}

Submitted on 6 Dec 2021

HAL is a multi-disciplinary open access archive for the deposit and dissemination of scientific research documents, whether they are published or not. The documents may come from teaching and research institutions in France or abroad, or from public or private research centers.
L'archive ouverte pluridisciplinaire HAL, est destinée au dépôt et à la diffusion de documents scientifiques de niveau recherche, publiés ou non, émanant des établissements d'enseignement et de recherche français ou étrangers, des laboratoires publics ou privés. 


\title{
Challenging pollution and the balance problem from
}

\author{
rare earth extraction: how recycling and
}

\author{
environmental taxation matter
}

Bocar Samba Ba* $\quad$ Pascale Combes-Motel ${ }^{\dagger} \quad$ Sonia Schwartz

\begin{abstract}
Rare earth element extraction induces environmental damages and the balance problem. In this article, we show that recycling can challenge both problems in a two-period framework. We also find other results depending on the amount of scrap that can be recycled. If the recycling activity is not limited by available scrap, it does not change extraction in first period. Environmental taxes on extracted quantities reduce extraction and favor recycling. But if the recycling is limited, the extractor reduces extraction in period one, adopting a foreclosure strategy and environmental taxes can decrease recycling. In all cases, environmental taxes are

*Terres Univia, 11 rue Monceau - CS 60003 - 75378 Paris Cedex 08. Email: bs.ba@terresunivia.fr

†Université Clermont Auvergne, IRD, CNRS, CERDI, F-63000 Clermont-Ferrand, France. Email: pascale.motel_combes@uca.fr

${ }^{\ddagger}$ Corresponding author. Université Clermont Auvergne, IRD, CNRS, CERDI, F-63000 ClermontFerrand, France. Email: sonia.schwartz@uca.fr
\end{abstract}


never equal to the marginal damage from pollution, in order to take into account the recycling effect.

Keywords: Rare Earth Elements, Pollution, Balance Problem, Recycling, Pigouvian Taxation, Cournot Competition.

JEL Codes: L13, L72, Q53, Q58. 


\section{Introduction}

Rare Earth Elements (REEs) are now vital for a vast array of modern technologies related to the transition to a low carbon economy such as energy generation and storage, energy efficient lights, electric cars and catalytic converters as well as military and aerospace applications (Golev et al. 2014). ${ }^{1}$ According to the US Geological Service (USGS) Mineral Commodity Summaries (2016), REEs reserves worldwide amount to 130 million tons. China and Brazil hold the largest shares of such reserves with respectively $16.9 \%$ and 42.3\%, followed by Australia (2.5\%), India (2.4\%) and the United States (2\%). Regarding mine extraction, out of the 124,000 metric tons estimated to have been produced in 2015, China contributed with $87.5 \%$, followed by Australia $8.3 \%$ and the United States $3.4 \%$ (Fernandez, 2017). If the USA long dominated the rare earth industry from the mid-1960s to the mid-1980s, China has become the main producer and now holds a quasi-monopoly. This leading status is mainly attributed to lower labor costs and lower environmental standards (Campbell, 2014; Muller et al. 2016).

REEs processing is water and energy-intensive and requires chemicals use (EPA, 2012). The mining and processing of REEs usually result in significant environmental impacts despite increasing efforts towards more efficient waster management (see e.g. An et al., 2019, for the case of industrial waste management utilities in China). Many deposits are actually characterized by high concentrations of radioactive elements such as uranium and thorium (Massari and Ruberti, 2013) and acidic substances (Elshkaki and Graedel, 2014) that are released into the environment without being treated (Folger, 2011). The

\footnotetext{
${ }^{1}$ The REEs constitute a group of 17 chemically similar metallic elements, composed of 15 lanthanide elements (lanthanum, cerium, praseodymium, neodymium, promethium, samarium, europium, gadolinium, terbium, dysprosium, holmium, erbium, thulium, ytterbium, and lutetium) and two other elements (scandium and yttrium).
} 
Asian Rare Earth company which was located in Malaysia between 1982 and 1992 has often been reported as an example of radioactive pollution associated with the processing of monazite ores (Ichihara and Harding, 1995). In China, mining of abundant ionic clay resources induces significant damages due to severe erosion, air, water and soil pollution, as well as biodiversity loss (Packey and Kingsnorth, 2016). Human health issues are also reported. The case of Baotou in Inner Mongolia is an emblematic location of which inhabitants are affected by cancers, respiratory diseases, and dental losses (Schüler et al., 2011) whereas the radioactive sludge lake makes the land around this city unsuitable for agriculture.

Despite their name, REEs are not all rare (Falconnet, 1985; Wübbeke, 2013). Rare earth ores contain one or several of the 17 elements, which makes several elements relatively abundant compared to others. The balance problem arises when the market demand for several REEs is not balanced with their natural abundance in REE ores (Elshkaki and Graedel, 2014). It is a major concern for extractors in that they bear storage costs for abundant REEs. For them, the balance problem is a more important issue than the availability of REEs. For instance, some REEs such as neodymium, dysprosium, terbium, and lanthanum are not abundant and are high in demand (Binnemans, 2014; Binnemans and Jones, 2015), whereas other elements such as cerium are abundant and low in demand (Golev et al., 2014). ${ }^{2}$

Several options have been proposed so far to mitigate the balance problem (Binnemans, 2014; Binnemans et al. 2013; Binnemans and Jones, 2015). In this paper, we focus

\footnotetext{
${ }^{2}$ For illustration, the forecast supply for neodymium and dysprosium in 2016 were respectively 3035,000 tons and 1,300-1,600 tons, while the forecast demand amounted respectively to 25-30,000 tons and 1,500-1,800 tons. The forecast supply for cerium was 75-85,000 tons, whereas the forecast demand was 60-70,000 tons (Kingsnorth, 2012).
} 
on the recycling of REEs that could postpone the extraction (Ba and Mahenc, 2018) and contribute to enhancing environmental quality (Duraiappah et al., 2002). For example, the supply of neodymium and dysprosium from their recycling is expected to cover about 5\% of the demand by 2050 (Elshkaki and Graedel, 2013). Several countries and corporations have already started to recycle REEs. China recovers REEs up to a maximum level of $95 \%$ (Yang et al., 2014) while Japan recycles a third of REEs used in the production of magnets (Hetzel and Bataille, 2014). The Solvay Group has recently developed the process for recovering REEs from lamp phosphors, batteries, magnets, and tailings in France and in Belgium (Binnemans et al., 2013). Hitachi Ltd has devised technologies to recycle rare earth magnets from hard disk drives (Hitachi, 2010 cited in Binnemans et al., 2013). Osram is able to recover REEs from used phosphors (Binnemans and Jones, 2014). Other processes allow now to recover REEs from the scrap generated in the various end-uses sectors (Schüler et al., 2011). It is worth stressing that mining companies such as Molycorp have also implemented recycling schemes for magnets in order to reduce the overproduction of some abundant REEs (Binnemans et al., 2013). These efforts made by several companies are still insufficient (OECD, 2015). One can, therefore, wonder whether environmental policies can have an effect on the intensity of recycling.

Recycling has been the subject of several theoretical investigations. First, some papers focus on the relationship between recycling and natural resource exhaustion. André and Cerdà (2006), Weikard and Seyhan (2009) and Seyhan et al. (2012) show that recycling delays the depletion of these resources. Ba and Mahenc (2018) analyze how far taking into account recycling challenges the Hotelling rule. Several other papers explore the impact of recycling on market power. The results are somehow contradictory. One the one side, recycling does not substantially affect the extractor's long-run market power 
(see Gaskins, 1974; Swan, 1980; Martin, 1982; Suslow, 1986; Hollander and Lasserre, 1988 and Grant, 1999). On the other side, recycling increases the extractor's market power (see Gaudet and Van Long, 2003; Baksi and Long, 2009). Finally some papers analyze instruments that favor recycling (see, for example, Gupt, 2015 and Yokoo and Kinnaman, 2013).

The main purpose of this paper is to investigate how far recycling and environmental taxes can alter both the balance problem and the pollution generated by REEs extraction. To the best of our knowledge, our contribution is the first one that takes into account the balance problem in an economic framework. It is also the first one that designs environmental taxes in the presence of recycling.

There are two ways of modeling the production process of REEs. One the one side, the extraction is a joint production process. The valuation of the co-products ensures the profitability of extraction. On the other side, the extractor only cares about specific elements while others are byproducts. The latter only provide extra value to the mining project and do not influence the optimal extraction. Fizaine (2013) for instance analyses the link between mining byproducts and the primary products. This paper formalizes the equilibrium between the supply and the demand for the primary ore only. The price elasticity of the byproduct supply is null because the extractor overlooks it. Yet, an equilibrium exists on the byproduct market between the inelastic supply and the demand. Fizaine (2013) analyses the market of minor metals but does not address the balance problem, which is precisely what we intend to do in this paper.

We rely on a two-period framework where a monopolist extracts two types of REEs, namely abundant and non-abundant REEs. In the second period of the game, the monopolist engages in competition with one firm that recycles part of the non-abundant 
REEs consumed in the first period. This brings our model close to Ba and Mahenc's (2018). It is however different in that the pollution and the balance problem are both taken into account.

Our results are the following. We show that recycling always reduces extracted quantities whereby mitigating the balance problem and environmental damages. Other results depend on the amount of scrap that can be recycled. If the recycling activity is not limited by this quantity, it does not change extraction in the first period. Otherwise, the extractor adopts a foreclosure strategy in period one and reduces REEs' extraction. The existence of both pollution and market power in each period does not allow reaching the optimum. We, therefore, propose to implement environmental taxes on extracted quantities. If the environmental tax reduces extraction and favors recycling when recycling is not limited by the available scrap, it can decrease recycling in the opposite case. This result suggests that the regulator has to be very cautious if he wants using environmental taxes to indirectly favor recycling. The second-best levels of environmental taxes depend on the marginal damage, on the market power as well as on the recycling. It is also worth to notice that the environmental taxes are never equal to the marginal damage.

The remainder of the paper is structured as follows. Section 2 describes the assumptions of the model and the first-best outcome. We consider the decentralized economy with recycling in Section 3. In Section 4, we introduce an exogenous environmental regulation and second-best environmental taxation in Section 5. Section 6 concludes the paper. Technical proofs are relegated in the appendix. 


\section{The model}

In this section we present the assumptions of the model and, as a benchmark, the first-best outcome.

\subsection{Assumptions}

We consider a two-period model where one firm extracts REEs from one mine. The extracted ore contains abundant and non-abundant REEs. Let $x_{t}$ denote the supply of non-abundant REEs and $\bar{x}_{t}$ the supply of abundant REEs, where $t=1,2$ is a time index. Since both types of REEs are extracted from the same ore, the extraction of one type induces mechanically the extraction of the other type such that $\bar{x}_{t}=\alpha x_{t}$, where $\alpha$ is a positive parameter. The extraction cost is denoted by $C_{t}\left(x_{t}\right)$ that has usual properties $\left(C^{\prime}>0\right.$ and $\left.C^{\prime \prime}>0\right)$. For the sake of simplification, we assume that the discount factor is normalized to one.

We assume that the market of non-abundant REEs is cleared while the supply of abundant REEs exceeds the demand such as $\bar{x}_{t}>x_{t}{ }^{d} \forall \bar{P}_{t} \geqslant 0$, where $x_{t}{ }^{d}$ is the demand of abundant REEs and $\bar{P}_{t}$ their unit price. ${ }^{3}$ The balance problem for abundant REEs incurs a storage cost borne by the extractor: $c_{s} \sum_{t=1}^{2}\left(\bar{x}_{t}-x_{t}^{d}\right)$, where $c_{s}>0$ is the marginal cost of storage.

In the first period, the extractor is a monopolist whereas it faces one recycler in the second period who recycles a quantity $r \leq k x_{1}$. The parameter $k$ denotes the recycling

\footnotetext{
${ }^{3}$ The equilibrium price for abundant REEs can be negative. In this case, the unbalance problem disappears. Concerning the over-the-counter price $\bar{P}_{t}$, our analysis remains valid if $\left.\bar{P}_{t} \in\right]-C s, 0[$ and does not match with the equilibrium price: these prices enable to sell abundant REEs out and to save storage costs.
} 
technology efficiency with $k \in] 0 ; 1]$. If the strict inequality $r<k x_{1}$ holds, it means that depreciation occurs during recycling. Note that the non-abundant REEs are recycled at a cost $C_{r}(r)$ that is an increasing and convex function.

Extracted and recycled quantity of non-abundant REEs are perfectly substitutable. $P_{t}$ is their prevailing market price. The inverse demand function is $P_{t}=P\left(Q_{t}\right)$ with $P^{\prime}<0$ and $P^{\prime \prime} \leqslant 0$. We note $Q_{t}$ the total quantity of non-abundant REEs supplied such as $Q_{1}=x_{1}$ and $Q_{2}=x_{2}+r$. We assume stationary demand functions.

We assume that the extraction of REEs causes pollution. The damage induced by REES therefore depends on the quantities extracted and not on a pollution stock. Hence the damage function that is written as $D\left(x_{t}\right)$ that is an increasing and convex function.

In the rest of the paper, our results depend crucially on whether $r \leq k x_{1}$. In order to ensure concavity in the extractor's profit and to have tractable results, we restrict our analysis to $P^{\prime \prime}=0$ and $C^{\prime \prime \prime}=0$ when $r=k x_{1}$.

\subsection{The first-best outcome}

We define the first-best outcome as a situation where there is no market power and strategic interactions and that takes into account environmental damages. We consider a benevolent regulator acting under perfect information. He maximizes a social welfare under the constraint on available scrap that can be used by the recycler. The program of the regulator is the following:

$$
\begin{gathered}
\operatorname{Max} W\left(x_{1}, x_{2}, r, \lambda\right)=\int_{0}^{x_{1}} P(u) d u+S c\left(x_{1}^{d}\right)+x_{1}^{d} \bar{P}_{1}-C_{1}\left(x_{1}\right)-c_{s}\left[\alpha x_{1}-x_{1}^{d}\right]-D\left(x_{1}\right) \\
+\int_{0}^{x_{2}+r} P(z) d z+S c\left(x_{2}^{d}\right)+x_{2}^{d} \bar{P}_{2}-C_{2}\left(x_{2}\right)-c_{s}\left[\alpha x_{1}+\alpha x_{2}-x_{1}^{d}-x_{2}^{d}\right]-C_{r}(r)-D\left(x_{2}\right) \\
\text { s.t. } r \leq k x_{1}
\end{gathered}
$$


where $\lambda$ is a Kuhn-Tucker multiplier and $S c\left(x_{1}^{d}\right)$ and $S c\left(x_{2}^{d}\right)$ the consumer surplus from abundant REEs. The first-order conditions are:

$$
\begin{gathered}
P_{1}\left(x_{1}\right)-C_{1}^{\prime}\left(x_{1}\right)-2 \alpha c_{s}-D^{\prime}\left(x_{1}\right)+\lambda k=0 \\
P_{2}\left(x_{2}+r\right)-C_{2}^{\prime}\left(x_{2}\right)-\alpha c_{s}-D^{\prime}\left(x_{2}\right)=0 \\
P_{2}\left(x_{2}+r\right)-C_{r}^{\prime}(r)-\lambda=0 \\
\lambda\left[k x_{1}-r\right]=0
\end{gathered}
$$

Let us explore the first-best outcome by distinguishing the following two cases:

The no-binding case: When the recycling constraint is not binding i.e. $r<k x_{1}$ and $\lambda=0$, we get after several rearrangements of (2), (3) and (4):

$$
\begin{aligned}
P_{1}\left(x_{1}^{* n c}\right) & =C_{1}^{\prime}\left(x_{1}^{* n c}\right)+2 \alpha c_{s}+D^{\prime}\left(x_{1}^{* n c}\right) \\
P_{2}\left(x_{2}^{* n c}+r^{* n c}\right) & =C_{2}^{\prime}\left(x_{2}^{* n c}\right)+\alpha c_{s}+D^{\prime}\left(x_{2}^{* n c}\right) \\
P_{2}\left(x_{2}^{* n c}+r^{* n c}\right) & =C_{r}^{\prime}\left(r^{* n c}\right)
\end{aligned}
$$

where the superscript $* n c$ means the non constrained first-best. In this case, the REEs value set in each period is equal to the private marginal costs augmented by the marginal environmental damage induced by extraction. Recycling and extracted quantities in period 2 are such that social marginal costs of production are identical. We find: $\frac{\partial x_{1}^{* n c}}{\partial c_{s}}<$ $0, \frac{\partial x_{2}^{* n c}}{\partial c_{s}}<0, \frac{\partial r^{* n c}}{\partial c_{s}}>0$ (see Appendix 1A). The balance problem leads to a decrease in extracted quantities in both periods and favors the recycling.

The binding case: When the recycling constraint is binding, we have $r=k x_{1}$ and $\lambda>0$. Rearranging Equations (2), (3) and (4) gives the following optimal conditions:

$$
\begin{gathered}
P_{1}\left(x_{1}^{* c}\right)-C_{1}^{\prime}\left(x_{1}^{* c}\right)-2 \alpha c_{s}-D^{\prime}\left(x_{1}^{* c}\right)+k\left[P_{2}\left(x_{2}^{* c}+k x_{1}^{* c}\right)-C_{r}^{\prime}\left(k x_{1}^{* c}\right)\right]=0 \\
P_{2}\left(x_{2}^{* c}+k x_{1}^{* c}\right)-C_{2}^{\prime}\left(x_{2}^{* c}\right)-\alpha c_{s}-D^{\prime}\left(x_{2}^{* c}\right)=0
\end{gathered}
$$


where the superscript $* c$ refers to the constrained first-best. The regulator defines the level of the quantity extracted in period 1 taking into account the impact of this extraction during period 2. We find: $\frac{\partial x_{1}^{* c}}{\partial c_{s}}<0, \frac{\partial x_{2}^{* c}}{\partial c_{s}}<0$ and $\frac{\partial r^{* c}}{\partial c_{s}}<0$ (see Appendix 2A). If the balance problem reduces extraction in both periods, it also reduces the level of recycled quantities.

From Eqs. (9) and (6), the extracted quantities in period 1 are higher in the binding case than in the no-binding case: at the first-best - due to the convex damage function - the regulator allows an increase in the damage in the first period in order to favor recycling in period $2 .{ }^{4}$

\section{The recycling}

In this section, we analyze the effect of recycling in the decentralized economy. We first investigate the economy without recycling then with recycling.

\subsection{Equilibrium without recycling}

Without recycling, the extractor acts as a monopolist in both periods. The profit of the extractor is the sum of revenues earned in both periods from selling both types of REEs minus extraction and storage costs:

$\pi^{e}\left(x_{1}, x_{2}\right)=P_{1}\left(x_{1}\right) x_{1}-C_{1}\left(x_{1}\right)-c_{s}\left[\bar{x}_{1}-x_{1}^{d}\right]+x_{1}^{d} \bar{P}_{1}+P_{2}\left(x_{2}\right) x_{2}-C_{2}\left(x_{2}\right)+x_{2}^{d} \bar{P}_{2}-c_{s}\left[\bar{x}_{1}-x_{1}^{d}+\bar{x}_{2}-x_{2}^{d}\right]$

\footnotetext{
${ }^{4}$ Several elements explain the main underlying mechanisms and trade-offs in this framework (in the binding or not binding case). First, without discounting and recycling, the convexity in damage function exerts a force toward smoothing extraction evenly over the two periods. Second, convexity in extraction and recycling costs implies that the recycling is welfare improving because it allows to split the extraction level in period 2 into two, lowering the average cost.
} 
First-order conditions take into account the relationship between both types of REEs:

$$
\begin{aligned}
& P_{1}\left(x_{1}^{w r}\right)+P_{1}^{\prime}\left(x_{1}^{w r}\right) x_{1}^{w r}-C_{1}^{\prime}\left(x_{1}^{w r}\right)-2 \alpha c_{s}=0 \\
& P_{2}\left(x_{2}^{w r}\right)+P_{2}^{\prime}\left(x_{2}^{w r}\right) x_{2}^{w r}-C_{2}^{\prime}\left(x_{2}^{w r}\right)-\alpha c_{s}=0
\end{aligned}
$$

where the superscript $w r$ means without recycling. Equations (11) and (12) indicate that in each period the price of the non-abundant REEs is equal to the sum of the marginal costs of extraction and storage, adjusted for the monopoly market power. The balance problem, by introducing storage costs, leads to reduce extraction in each period. The reduction is more pronounced in period 1 because the storage cost is reduced in period 2. We have:

$$
x_{1}^{w r}<x_{2}^{w r}
$$

Proposition 1 Due to the balance problem, extracted quantities without recycling in period 2 are higher than extracted quantities in period 1.

It is fair to state that this result is (likely) not robust to the extension to the infinite horizon. If we relax the assumption of stationary demand functions, Proposition 1 does not hold anymore. For example, if the demand shrinks sufficiently from period 1 to period 2, first period production could be larger than second period production. In the same vein, if we introduce a discount factor, the extractor undervalues the storage cost borne in period 2. Hence it increases extraction in period 1 compared to the case where the discount factor is equal to one.

\subsection{Equilibrium with recycling}

Recycling occurs only in the second period. Using backward induction, we first find the equilibrium quantities in period 2 and we then solve for the quantity produced by the 
extractor in period 1.

\subsubsection{The second stage: the equilibrium quantities in period 2}

Let us define the subgame-perfect Nash equilibrium in period 2. The extractor's profit function in the second period is the following:

$$
\pi^{e}\left(x_{2}, r\right)=P_{2}\left(x_{2}+r\right) x_{2}-C_{2}\left(x_{2}\right)+x_{2}^{d} \bar{P}_{2}-c_{s}\left[\alpha x_{1}-x_{1}^{d}+\alpha x_{2}-x_{2}^{d}\right]
$$

The FOC gives:

$$
P_{2}\left(x_{2}+r\right)+P_{2}^{\prime}\left(x_{2}+r\right) x_{2}-C_{2}^{\prime}\left(x_{2}\right)-\alpha c_{s}=0
$$

The recycler maximizes its profit, subject to the constraint on the available resource:

$$
\begin{aligned}
\pi^{r}\left(r, x_{2}\right) & =P_{2}\left(x_{2}+r\right) r-C_{r}(r) \\
r & \leq k x_{1}
\end{aligned}
$$

We find:

$$
\left\{\begin{array}{l}
P_{2}\left(x_{2}+r\right)+P_{2}^{\prime}\left(x_{2}+r\right) r-C_{r}^{\prime}(r)=0 \text { if } r<k x_{1} \\
r=k x_{1} \text { otherwise }
\end{array}\right.
$$

which represents the recycler best response function. The equilibrium depends on whether the recycling constraint is binding (denoted by the superscript $c$ ) or not (denoted by the superscript $n c)$.

- If the available quantity of scrap is higher than the unconstrained profit-maximizing quantity, the extractor and the recycler produce the quantities that satisfy the following FOCs:

$$
\left\{\begin{array}{l}
P_{2}\left(x_{2}^{n c}+r^{n c}\right)+P_{2}^{\prime}\left(x_{2}^{n c}+r^{n c}\right) x_{2}^{n c}-C_{2}^{\prime}\left(x_{2}^{n c}\right)-\alpha c_{s}=0 \\
P_{2}\left(x_{2}^{n c}+r^{n c}\right)+P_{2}^{\prime}\left(x_{2}^{n c}+r^{n c}\right) r^{n c}-C_{r}^{\prime}\left(r^{n c}\right)=0
\end{array}\right.
$$


The Implicit Function Theorem on FOCs given by (14) shows that reaction functions are decreasing. The recycled scrap and the extracted output are strategic substitutes. Recycling reduces the quantity of non-abundant REEs which is extracted by the monopolist in the second period. This behavior was coined the "business-stealing" effect after Mankiw and Whinston (1986). The strategic response of existing firms to new entry results in reducing their production when a new entrant "steals business" from incumbent firms. Solving the system given by (14) gives the non-constrained subgame-perfect Nash equilibrium $\left(x_{2}^{n c}, r^{n c}\right)$. The extracted quantities and the level of recycled scrap in period 2 do not depend on the quantity extracted in period $1 .^{5}$

- If the available quantity of scrap is lower than the unconstrained profit-maximizing quantity, the equilibrium in period 2 is given by:

$$
\left\{\begin{array}{l}
P_{2}\left(x_{2}^{c}+r^{c}\right)+P_{2}^{\prime}\left(x_{2}^{c}+r^{c}\right) x_{2}^{c}-C_{2}^{\prime}\left(x_{2}^{c}\right)-\alpha c_{s}=0 \\
r=k x_{1}^{c}
\end{array}\right.
$$

Solving this system gives the constrained subgame-perfect Nash equilibrium $\left(x_{2}^{c}, r^{c}\right)$. We find $x_{2}^{c}=f\left(x_{1}\right)$, with $\frac{d x_{2}^{c}}{d x_{1}}<0$. Hence, the extraction level in period 1 will affect the level of recycling as well the extracted quantity in period 2.

Proposition 2 Whatever the level of recycled scrap, the recycling activity reduces extraction in the second period.

\subsubsection{The first stage: the equilibrium quantities in period 1}

In order to obtain the equilibrium quantity in period 1, we replace equilibrium quantities in period 2 in the extractor's profit function. The quantity in the first stage depends on

\footnotetext{
${ }^{5}$ We note that $\left(x_{2}^{n c}, r^{n c}\right)$ do not depend on $x_{1}$ if the recycling quantity is lower than the threshold, but this threshold depends on $x_{1}$.
} 
the subgame-perfect Nash equilibrium obtained in the second stage.

The no-binding case: If the available quantity of scrap does not constrain the recycler from producing, we find:

$$
\begin{aligned}
\pi^{e}\left(x_{1}, x_{2}^{n c}, r^{n c}\right)= & P_{1}\left(x_{1}\right) x_{1}-C_{1}\left(x_{1}\right)+x_{1}^{d} \bar{P}_{1}-c_{s}\left[\alpha x_{1}-x_{1}^{d}\right] \\
& +P_{2}\left(x_{2}^{n c}+r^{n c}\right) x_{2}^{n c}-C_{2}\left(x_{2}^{n c}\right)+x_{2}^{d} \bar{P}_{2}-c_{s}\left[\alpha x_{1}-x_{1}^{d}+\alpha x_{2}^{n c}-x_{2}^{d}\right]
\end{aligned}
$$

The FOC is:

$$
P_{1}\left(x_{1}^{n c}\right)+P_{1}^{\prime}\left(x_{1}^{n c}\right) x_{1}^{n c}-C_{1}^{\prime}\left(x_{1}^{n c}\right)-2 \alpha c_{s}=0
$$

Recycling does not affect the quantity of REEs extracted by the monopolist in the first period (Equation 16 is similar to Equation 11). As expressed above, recycling slowdowns extraction in the second period. Thus, recycling helps to mitigate the balance problem by reducing the stock of abundant REEs and contributes also to reduce pollution in the second period. As far as total quantities traded in period 2, we find

$$
Q_{2}^{n c} \gtrless Q_{1}^{n c}=Q_{1}^{w r}
$$

On the one hand, without recycling, the storage cost induces more extraction in the second period than in the first period. On the other hand, recycling reduces extraction in the second period. Thus, depending on the magnitude of the storage cost, the total quantities can either increase or decrease between periods 1 and 2 .

Moreover we find that (see Appendix 1B):

$$
\frac{\partial x_{1}^{n c}}{\partial c_{s}}<0 ; \frac{\partial x_{2}^{n c}}{\partial c_{s}}<0 ; \frac{\partial r^{n c}}{\partial c_{s}}>0
$$

If the storage costs reduces extracted quantities in each period, they boost the recycled quantity in period 2. The effects of the balance problem are similar to ones under "firstbest". 
Proposition 3 In the no-binding case, recycling does not change extraction in period 1. The balance problem favors recycling in period 2 and mitigates environmental damages in both periods.

The binding case: If the collected scrap constrains the production level of the recycler, the profit of the extractor reads as follows:

$$
\begin{aligned}
\pi^{e}\left(x_{1}\right)= & \left.P_{1}\left(x_{1}\right) x_{1}-C_{1}\left(x_{1}\right)+x_{1}^{d} \bar{P}_{1}-c_{s}\left[\alpha x_{1}-x_{1}^{d}\right]+P_{2}\left(x_{2}^{c}\left(x_{1}\right)+k x_{1}\right)\right) x_{2}^{c}\left(x_{1}\right)-C_{2}\left(x_{2}^{c}\left(x_{1}\right)\right) \\
& +x_{2}^{d} \bar{P}_{2}-c_{s}\left[\alpha x_{1}-x_{1}^{d}+\alpha x_{2}^{c}\left(x_{1}\right)-x_{2}^{d}\right]
\end{aligned}
$$

The FOC is the following:

$$
P_{1}\left(x_{1}^{c}\right)+P_{1}^{\prime}\left(x_{1}^{c}\right) x_{1}-C_{1}^{\prime}\left(x_{1}^{c}\right)-2 \alpha c_{s}+\frac{d x_{2}^{c}\left(x_{1}^{c}\right)}{d x_{1}^{c}}\left[P_{2}\left(x_{1}^{c}\right)+P_{2}^{\prime}\left(x_{1}^{c}\right) x_{2}^{c}\left(x_{1}^{c}\right)-C_{2}^{\prime}\left(x_{1}^{c}\right)-\alpha c_{s}\right]+k P_{2}^{\prime}\left(x_{1}^{c}\right) x_{2}^{c}\left(x_{1}^{c}\right)=0
$$

Comparing Equations (16) and (17) gives $x_{1}^{c}<x_{1}^{n c}$. Contrary to the no-binding case, recycling reduces the first period extracted quantity of REEs. By reducing extraction, the extractor, acting as a leader, curtails recycling in the second period. That enables reducing future competition. The extractor adopts a foreclosure strategy in order to keep strong market power in period 2. Hence, recycling strengthens the market power in period 1. At last, we obtain the following result on global quantities:

$$
Q_{2}^{n c} \gtrless Q_{1}^{c}
$$

We also find (see Appendix B2):

$$
\frac{\partial x_{1}^{c}}{\partial c_{s}}<0 ; \frac{\partial x_{2}^{c}}{\partial c_{s}}<0 ; \frac{\partial r^{c}}{\partial c_{s}}<0
$$

If a high storage cost favors recycling in the non-binding case, it reduces recycling if $r=$ $k x_{1}$. In this case, the balance problem indirectly limits recycling and, hence, competition in the second period. 
Proposition 4 In the binding case, recycling leads to foreclosure behavior in the first period. $^{6} \quad$ The balance problem limits recycling and, hence, triggers the environmental damages in the second period.

Comparing equations (14)-(16) with (6)-(7)-(8) and (15)-(17) with (10) shows that the market equilibrium never reaches the first-best. In each case, the storage cost of abundant REEs induces the extractor to take the balance problem into account. Both market power and pollution, however, prevent reaching the first-best outcome. As widely acknowledged in the literature, one way to restore the social optimum is to tax negative externalities. In the sequel, we will analyze what will happen with the implementation of a tax scheme by the benevolent regulator.

\section{Exogenous environmental regulation}

In order to internalize the negative externality, i.e. pollution induced by extraction, the regulator sets environmental taxes $\tau_{t}$, that it levies on each extracted unity in each period. As in Section 3, we solve the game by backward induction. We first define equilibrium quantities in period 2 , then in period 1.

\footnotetext{
${ }^{6}$ In Ba and Mahenc (2018) the extractor always reduces its extraction in period 1 expecting recycling in period 2. But contrary to our paper, this behavior depends on a fixed cost borne by the recycler. Moreover they assume that the resource is exhausted in period 2.
} 


\subsection{The second stage: the equilibrium quantities in period 2}

If an environmental tax is levied on the extraction, the extractor's profit maximization program in period 2 becomes:

$$
\pi^{e}\left(x_{1}, x_{2}, r\right)=P_{2}\left(x_{2}+r\right) x_{2}-C_{2}\left(x_{2}\right)+y_{2}^{d} \bar{P}_{2}-c_{s}\left[\alpha x_{1}-y_{1}^{d}+\alpha x_{2}-y_{2}^{d}\right]-\tau_{2} x_{2}
$$

The profit function of the recycler is not modified by the environmental taxation. Extracted quantities in period 2 depend on the constraint on recycling:

- If the available quantity is higher than the unconstrained profit-maximizing quantity, the extractor and the recycler produce the quantities that satisfy the following FOCs:

$$
\left\{\begin{array}{l}
P_{2}\left(x_{2}^{n c t}+r^{n c t}\right)+P_{2}^{\prime}\left(x_{2}^{n c t}+r^{n c t}\right) x_{2}^{n c t}-C_{2}^{\prime}\left(x_{2}^{n c t}\right)-\alpha c_{s}-\tau_{2}=0 \\
P_{2}\left(x_{2}^{n c t}+r^{n c t}\right)+P_{2}^{\prime}\left(x_{2}^{n c t}+r^{n c t}\right) r^{n c t}-C_{r}^{\prime}\left(r^{n c t}\right)=0
\end{array}\right.
$$

Solving this system gives the unconstrained subgame-perfect Nash equilibrium $\left(x_{2}^{n c t}\left(\tau_{2}\right), r^{n c t}\left(\tau_{2}\right)\right)$, with $\frac{\partial x_{2}^{n c t}}{\partial \tau_{2}}<0$ and $\frac{\partial r^{n c t}}{\partial \tau_{2}}>0$ (see Appendix A3). Equilibrium quantities in period 2 do not depend on the extracted quantities in period 1.

- If the recycler is limited by the available quantity of scrap, the constrained subgameperfect Nash equilibrium is given by:

$$
\left\{\begin{array}{l}
P_{2}\left(x_{2}^{c t}+r^{c t}\right)+P_{2}^{\prime}\left(x_{2}^{c t}+r^{c t}\right) x_{2}^{c t}-C_{2}^{\prime}\left(x_{2}^{c t}\right)-\alpha c_{s}-\tau_{2}=0 \\
r^{c t}=k x_{1}
\end{array}\right.
$$

Solving this system gives $x_{2}^{c t}\left(x_{1}, \tau_{2}\right)$, with $\frac{\partial x_{2}^{c t}}{\partial x_{1}}<0$.

\subsection{The first stage: the equilibrium quantities in period 1}

Quantities in period 1 depend on the outcome of the subgame-perfect Nash equilibrium. 
The no-binding case. If $r<k x_{1}$, quantities in period 2 do not depends on $x_{1}$. The extractor maximizes its profit in the first period. We have:

$$
\begin{gathered}
\pi^{e}\left(x_{1}\right)=\quad P_{1}\left(x_{1}\right) x_{1}-C_{1}\left(x_{1}\right)+x_{1}^{d} \bar{P}_{1}-c_{s}\left[\alpha x_{1}-y_{1}^{d}\right]-\tau_{1} x_{1}+P_{2}\left(x_{2}^{n c t}+r^{n c t}\right) x_{2}^{n c t}-C_{2}\left(x_{2}^{n c t}\right) \\
+y_{2}^{d} \bar{P}_{2}-c_{s}\left[\alpha x_{1}-y_{1}^{d}+\alpha x_{2}^{n c t}-y_{2}^{d}\right]-\tau_{2} x_{2}^{n c t} \\
P_{1}\left(x_{1}^{n c t}\right)+P_{1}^{\prime}\left(x_{1}^{n c t}\right) x_{1}-C_{1}^{\prime}\left(x_{1}^{n c t}\right)-2 \alpha c_{s}-\tau_{1}=0
\end{gathered}
$$

If we compare Equation (20) to Equation (16), we show that the extractor reduces the extracted quantity in period 1 under environmental taxation. Solving Equation (20) enables to obtain $x_{1}^{n c t}$ as a function of $\tau_{1}$, with $\frac{\partial x_{1}^{n c t}}{\partial \tau_{1}}<0$ (Appendix A3). Each perperiod extracted quantity decreases with the per-period tax rate. Hence taxes increase the recycled output, since recycling and the second period extracted output are strategic substitutes.

Proposition 5 When the recycling activity is not bounded by the available scrap, environmental taxation favors recycling.

The binding case. We replace $x_{2}^{c t}\left(x_{1}, \tau_{2}\right)$ and $r^{c t}=k x_{1}$ in the profit of the extractor. We obtain:

$$
\begin{aligned}
\pi^{e}\left(x_{1}\right)= & P_{1}\left(x_{1}\right) x_{1}-C_{1}\left(x_{1}\right)+x_{1}^{d} \bar{P}_{1}-c_{s}\left[\alpha x_{1}-y_{1}^{d}\right]-\tau_{1} x_{1}+P_{2}\left(x_{2}^{c t}\left(x_{1}, \tau_{2}\right)+k x_{1}\right) x_{2}^{c t}\left(x_{1}, \tau_{2}\right) \\
& -C_{2}\left(x_{2}^{c t}\left(x_{1}, \tau_{2}\right)\right)+y_{2}^{d} \bar{P}_{2}-c_{s}\left[\alpha x_{1}-y_{1}^{d}+\alpha x_{2}^{c t}\left(x_{1}, \tau_{2}\right)-y_{2}^{d}\right]-\tau_{2} x_{2}^{c t}\left(x_{1}, \tau_{2}\right)
\end{aligned}
$$

The FOC reads as follows:

$$
P_{1}+P_{1}^{\prime} x_{1}^{c t}-C_{1}^{\prime}-2 \alpha c_{s}-\tau_{1}+\frac{\partial x_{2}^{c t}}{\partial x_{1}^{c t}}\left[P_{2}^{\prime} x_{2}^{c t}+P_{2}-C_{2}^{\prime}-\alpha c_{s}-\tau_{2}\right]+P_{2}^{\prime} k x_{2}^{c t}=0
$$

Solving Equation $(21)$ gives $x_{1}^{c t}\left(\tau_{1}, \tau_{2}\right)$ and hence $x_{2}^{c t}\left(\tau_{1}, \tau_{2}\right)$ with $\frac{d x_{1}^{c t}}{d \tau_{1}}=\frac{d x_{2}^{c t}}{d \tau_{2}}<0$ and $\frac{d x_{1}^{c t}}{d \tau_{2}}=\frac{d x_{2}^{c t}}{d \tau_{1}}>0$ (see Appendix B3). Depending on $\tau_{1}$ and $\tau_{2}$, the extracted quantities in 
the first period (second period) can increase if $\tau_{2}\left(\tau_{1}\right)$ is high enough. Hence the recycling activity increases with the tax in the second period - as in the binding case - but decreases with the tax in the first period. Thus environmental taxes can disadvantage recycling activity.

Proposition 6 Environmental taxation can reduce recycling when the recycling activity is limited by available scrap.

\section{The second-best environmental regulation}

The regulator determines the second-best environmental taxes ${ }^{7}$ maximizing the welfare function (given by Equation (1)), replacing quantities depending on the tax levels found in the preceding section. ${ }^{8}$ The solution depends on the subgame-perfect Nash equilibrium, i.e. whether the recycler is limited or not by the collected scrap quantity.

\subsection{The no-binding case}

We replace $x_{1}^{n c t}\left(\tau_{1}\right), x_{2}^{n c t}\left(\tau_{2}\right)$ and $r^{n c t}\left(\tau_{2}\right)$ in the welfare function that we maximize with respect to $\tau_{1}$ and $\tau_{2}$. The first-order conditions are the following:

$$
\begin{aligned}
& \frac{d x_{1}}{d \tau_{1}}\left[P_{1}\left(x_{1}\right)-C_{1}^{\prime}\left(x_{1}\right)-2 \alpha c_{s}-D^{\prime}\left(x_{1}\right)\right]=0 \\
& \frac{d x_{2}}{d \tau_{2}}\left[P\left(x_{2}+r\right)-C_{2}^{\prime}\left(x_{2}\right)-\alpha c_{s}-D^{\prime}\left(x_{2}\right)\right]+\frac{d r}{d \tau_{2}}\left[P_{2}\left(x_{2}+r\right)-C_{r}^{\prime}(r)\right]=0
\end{aligned}
$$

\footnotetext{
${ }^{7}$ See Buchanan (1969); Barnett (1980); Levin (1985); Simpson (1995) and, among others, David and Sinclair-Desgagné (2005).

${ }^{8}$ The welfare function is maximized without taking into account the constraint on available scrap: this constraint has already been taken into account in the quantities determination in Section 4 .
} 
Substituting (18) and (20) into (22) yields the following pair of tax rates:

$$
\begin{aligned}
\tau_{1}^{n c t} & =\underbrace{D^{\prime}\left(x_{1}\right)+P^{\prime}\left(x_{1}\right)}_{\text {Usual result }} x_{1} \\
\tau_{2}^{n c t} & =\underbrace{D^{\prime}\left(x_{2}\right)+P^{\prime}\left(x_{2}+r\right) x_{2}}_{\text {Usual result }}+\underbrace{\frac{\frac{d r\left(\tau_{2}\right)}{d \tau_{2}}}{\frac{d x_{2}\left(\tau_{2}\right)}{d \tau_{2}}}\left[P_{2}^{\prime}\left(x_{2}+r\right) r\right]}_{\text {Recycling effect }}
\end{aligned}
$$

The tax rate in period 1 depends only on the active distortions over this period. One

is the distortion from the negative externality generated by the pollution, the other is the distortion from the extractor's market power in the market of non-abundant REEs. Since $P_{1}^{\prime}\left(x_{1}\right)<0$, the tax rate is lower than the marginal damage (see Barnett, 1980). ${ }^{9}$ The benevolent regulator sets the tax at this level in order to reduce the tendency of the monopolist to underproduce. In this case, the tax could be either positive or negative. Its sign depends on the prevailing distortion. If the distortion from the environmental damage is larger than the distortion from the extractor's market power, i.e. $D^{\prime}\left(x_{1}\right)>-P_{1}^{\prime}\left(x_{1}\right) x_{1}$, then $\tau_{1}^{n c t}>0$ and turns out to be a tax. Otherwise, $\tau_{1}^{n c t}<0$ and $\tau_{1}^{n c t}$ is a subsidy. It is worth noting that recycling does not influence the first period tax rate because it does not affect the extraction in that period.

According to Equation (23), the second-period tax depends only on distortions in this period. It is also composed of both usual distortions but is adjusted by an additional term emanating from the recycling activity. As $\frac{d r\left(\tau_{2}\right)}{d \tau_{2}} / \frac{d x_{2}\left(\tau_{2}\right)}{d \tau_{2}}<0$ and $\left[P_{2}^{\prime}\left(x_{2}+r\right) r\right]<0$, the recycling effect is positive. The regulator increases further the second period tax rate in order to foster recycling. If this recycling effect is strong enough, the second period

\footnotetext{
${ }^{9}$ In the case of one distortion in an economy - a negative externality - the first-best can be reached with an environmental tax set at the marginal damage, that is usually called "Pigouvian tax". Following Barnett (1980), an environmental tax designed with other imperfections is called a second-best optimal tax, that is not equal to the marginal damage. Barnett speaks about "the Pigouvian tax rule under monopoly".
} 
tax rate will be higher than the marginal damage. Note that the recycling effect catches the capacity of $\tau_{2}$ to modify the price in the second period. Thus the regulator increases the tax in the second period in order to both favor competition and reduce environmental damage. If we replace $\tau_{1}^{n c t}$ and $\tau_{2}^{n c t}$ in Equations (18) and (20), we find:

$$
\begin{gathered}
P\left(x_{1}\right)-C_{1}^{\prime}\left(x_{1}\right)-2 \alpha c_{s}-D^{\prime}\left(x_{1}\right)=0 \\
P\left(x_{2}+r\right)-C_{2}^{\prime}\left(x_{2}\right)-\alpha c_{s}-D^{\prime}\left(x_{2}\right)-\frac{\frac{d r\left(\tau_{2}\right)}{d \tau_{2}}}{\frac{d x_{2}\left(\tau_{2}\right)}{d \tau_{2}}} P^{\prime}\left(x_{2}+r\right) r=0
\end{gathered}
$$

As Equation (24) is similar to Equation (6), second-best environmental taxation in the first period enables to reach the first-best outcome. The tax internalizes both market failures induced by market power and pollution. As Eq. (25) is different from Eq. (7), a tax in period 2 cannot simultaneously cope with distortions enacted by market power and the environmental damage while taking into account the recycled output. Second-best taxation in the second period therefore enables to reach a second-best outcome.

The taxation effect on the balance problem depends on the sign of $\tau_{1}^{n c t}$ and $\tau_{2}^{n c t}$. The balance problem is enhanced if tax rates are negative. On the contrary, positive tax rates lead to reduced extracted quantities, whereby alleviating the balance problem.

Proposition 7 Due to market power, the second-best tax in period 1 is lower than the marginal damage which leads to achieve first-best quantity. In Period 2, recycling increases the tax whereas the market power reduces it. Finally the second-best tax level in period 2 can be higher than the marginal damage.

\subsection{The binding case}

In this case, we replace $x_{1}^{c t}\left(\tau_{1}, \tau_{2}\right), x_{2}^{c t}\left(\tau_{1}, \tau_{2}\right)$ and $r^{c t}\left(\tau_{1}, \tau_{2}\right)$ in the welfare function and we maximize with respect to $\tau_{1}$ and $\tau_{2}$. After rearranging the first-order conditions, we 
find:

$$
\begin{aligned}
& \frac{d x_{1}}{d \tau_{1}}\left[P_{1}\left(x_{1}\right)-C_{1}^{\prime}\left(x_{1}\right)-2 \alpha c_{s}-D^{\prime}\left(x_{1}\right)+P_{2}\left(x_{2}+k x_{1}\right) k-k C_{r}^{\prime}\left(k x_{1}\right)\right] \\
& +\frac{d x_{2}}{d \tau_{1}}\left[P_{2}\left(x_{2}+k x_{1}\right)-C_{2}^{\prime}\left(x_{2}\right)-\alpha c_{s}-D^{\prime}\left(x_{2}\right)\right]=0 \\
& \frac{d x_{1}}{d \tau_{2}}\left[P_{1}\left(x_{1}\right)-C_{1}^{\prime}\left(x_{1}\right)-2 \alpha c_{s}-D^{\prime}\left(x_{1}\right)+P_{2}\left(x_{2}+k x_{1}\right) k-k C_{r}^{\prime}\left(k x_{1}\right)\right] \\
& +\frac{d x_{2}}{d \tau_{2}}\left[P_{2}\left(x_{2}+k x_{1}\right)-C_{2}^{\prime}\left(x_{2}\right)-\alpha c_{s}-D^{\prime}\left(x_{2}\right)\right]=0
\end{aligned}
$$

Substituting (19) and (21) in (26), we find the following taxes:

$$
\begin{aligned}
\tau_{1}^{c t} & =\underbrace{P^{\prime}\left(x_{1}\right) x_{1}+D^{\prime}\left(x_{1}\right)}_{\text {Usual result }}-k\left[P_{2}\left(x_{2}+k x_{1}\right)-C_{r}^{\prime}\left(k x_{1}\right)-P_{2}^{\prime}\left(x_{2}+k x_{1}\right) x_{2}\right] \\
\tau_{2}^{c t} & =\underbrace{P_{2}^{\prime}\left(x_{2}+k x_{1}\right) x_{2}+D^{\prime}\left(x_{2}\right)}_{\text {Recycling effect }}
\end{aligned}
$$

As the quantity extracted in period 1 has an effect on period 2 , the design of $\tau_{1}^{c t}$ has to consider effects in both periods. The first two terms catch usual effects in period 1 and other terms take into account effects in period 2. $\tau_{1}^{c t}$ diminishes with the marginal profit of the recycler and with the price variation induced by recycling. Finally $\tau_{1}^{c t}$ is always inferior to the marginal damage so is $\tau_{2}^{c t}$. Replacing both taxes in (19) and (21) gives the equations (9) and (10). The regulator is able to implement the first-best outcome provided the recycling constraint is binding.

Proposition 8 Second-best taxation scheme enables to reach the first-best quantities in each period. Tax in period 1 (period 2) takes into account market power and recycling (market power). Both taxes are lower than the marginal damage.

\section{Conclusion}

The extraction of REEs raises serious pollution problems and leads to the balance problem. This paper analyzed theoretically the effect of recycling and environmental tax regulation on both the balance problem and pollution. It contributes to the theoretical 
analysis of green policies aiming at downscaling resource use while promoting recycling activities.

We set up a Cournot model where one firm involved in the extraction sector simultaneously supplies two types of REEs - abundant and non-abundant - over two consecutive periods. In the second period, it competes with a recycler of non-abundant REEs that are used in the first period. We first showed that recycling always reduces extracted quantities then mitigating both the balance problem and the environmental damages. Our results crucially depend on whether the recycler can recycle the whole quantity of scrap it wants. If its activity is not limited, the first period extracted quantities are unchanged. Otherwise, the extractor adopts a foreclosure strategy that consists in reducing its extraction in the first period. Because there are distortions in the economy (pollution and market power) both equilibria are not optimal. Owing to those distortions, secondbest environmental taxation is introduced in each period. We showed that environmental taxation always favors recycling when the constraint on the scrap availability does not bind whereas recycled quantities can decrease if the constraint binds. From this point of view, the regulator should pay cautious attention when shaping environmental taxation in order to indirectly favor recycling. In addition, we established that the second-best levels of environmental taxes depend on the marginal damage, on the market power as well as on the recycling.

This article is, according to our knowledge, the first to theoretically investigate the balance problem and to design environmental taxes in the presence of recycling. It can be considered as providing several theoretical insights that could be valuable for the proper functioning of the circular economy. It is important to notice that this normative analysis is conducted on a global scale since the extractor and the recycler do belong to the same 
economy. It, therefore, overlooks the fact that rare earth ores are mainly extracted in China and that recycling activities are disseminated in several countries. Taking into account this geopolitical specificity would deserve another game theoretical set-up i.e. a game between a monopoly and a competitive fringe under the assumption that REEs are traded without transportation costs. The environmental taxes would also be implemented in the extracting country while not taking into account the global consumer surplus, as it is done in this article - but only the consumer surplus from the quantity consumed in this country. These new assumptions would not fundamentally change the extractor strategy but, rather, the environmental tax levels. According to our results, if China implements environmental taxes on REEs extraction, recycling would not be necessarily boosted. China could instead strategically implement environmental taxes in order to reduce recycling if the available scrap is low.

This paper can be extended into several directions. We do not consider that the stock of unsold abundant REEs can be polluting. Likewise, we do not take into account that REEs recycling activity can also be polluting. This would lead the regulator to potentially consider other damages and, consequently, to introduce other environmental taxes. That would change the level of recycling and therefore extraction. We also neglect the strategic aspects for a country related to the holding of REEs. In this case, the regulator may wish to develop recycling to ensure the security of rare earth supply (Golev et al. 2014). An extension of our paper would be not to consider the balance problem but the environmental tax implementation when there is an equilibrium on the byproduct market. Lastly, it would be interesting to extend this model over infinite time in order to assess whether the asymmetry between periods would still hold. This analysis would take into account the REE stock. Further research is needed to investigate these different 
questions.

\section{References}

[1] An Y, Zhang L and Adom P (2019) Economics of wastewater management in China's industry. Environment and Development Economics 24(5), 457-478.

[2] Andre FJ and Cerdà E (2006) On the dynamics of recycling and natural resources. Environmental and Resource Economics 33, 199-221.

[3] Ba BS and Mahenc $\mathbf{P}$ (2018) Is recycling a threat or an opportunity for the extractor of an exhaustible resource? Environmental and Resource Economics, $10.1007 / \mathrm{s} 10640-018-0293-1$

[4] Baksi S and Long NV (2009) Endogenous consumer participation and the recycling problem. Australian Economic Papers 48(4), 281-295.

[5] Barnett AH (1980) The Pigovian tax under monopoly. American Economic Review 70(5), 1037-1340.

[6] Binnemans K (2014) Economics of rare earths: the balance problem, 1st European Rare Earths Resources Conference/Milos/.

[7] Binnemans K and Jones PT (2014) Perspectives for the recovery of rare earths from end-of-life fluorescent lamps. Journal of Rare Earths 32(3), 195.

[8] Binnemans K and Jones PT (2015) Rare Earths and the balance problem. Journal of Sustainable Metallurgy 1(1), 29-38. 
[9] Binnemans K, Jones PT, Acker KV, Blanpain B, Mishra B and Apelian D (2013) Rare earths economics: the balance problem. JOM 65(7), 846-848.

[10] Binnemans K, Jones PT, Blanpain B, Gerven TV, Yang Y, Walton A and Buchert M (2013) Recycling of rare earths: a critical review. Journal of Cleaner Production 51, 1-22.

[11] Buchanan J (1969) External diseconomies, corrective taxes, and market structure. The American Economic Review 59(1), 174-177.

[12] Campbell G (2014) Rare earth metals: a strategic concern. Mineral Economics $\mathbf{2 7}(1), 21-31$.

[13] David M and Sinclair-Desgagné B (2005) Environmental regulation and the eco-industry. Journal of Regulatory Economics 28(2), 141-155.

[14] Duraiappah AK, Xin Z and Van Beukering PJH (2002) Issues in production, recycling and international trade: analysing the Chinese plastic sector using an optimal life cycle (OLC) model. Environment and Development Economics 7(1), 47-74.

[15] Elshkaki A and Graedel TE (2013) Dynamic analysis of the global metals flows and stocks in electricity generation technologies. Journal of Cleaner Production 59, 260-73.

[16] Elshkaki A and Graedel TE (2014) Dysprosium, the balance problem, and wind power technology. Applied Energy, 136, 548-559.

[17] Falconnet $\mathbf{P}$ (1985) The economics of rare earths. Journal of the Less-Common Metals 111, 9-15. 
[18] Fernandez V (2017) Rare-earth elements market: A historical and financial perspective. Resources Policy, 53, 26-45.

[19] Fizaine F (2013) Byproduct production of minor metals: Threat or opportunity for the development of clean technologies? The PV sector as an illustration. Resources Policy 38, 373-383.

[20] Folger T (2011) The secret ingredients of everything. National Geographic Magazine, 6-11.

[21] Gaskins D (1974) Alcoa revisited: The welfare implications of a secondhand market. Journal of Economic Theory 7, 254-271.

[22] Gaudet G and Van Long N (2003) Recycling redux: A Nash-Cournot approach. The Japonese Economic Review 54(4), 409-419.

[23] Golev A, Scott M, Erskine PD, Ali SH and Ballantyne GR (2014) Rare earths supply chains: current status, constraints and opportunities. Resources Policy, $41,52-52$.

[24] Grant D (1999) Recycling and market power: a more general model and reevaluation of the evidence. International Journal of Industrial Organization 17, 5980.

[25] Gupt Y (2015) Economic instruments and the efficient recycling of batteries in Delhi and the National Capital Region of India. Environment and Development Economics, $\mathbf{2 0}(2), 236-258$. 
[26] Hetzel P and Bataille D (2014). Etudes de faisabilité de la saisine sur les enjeux stratégiques des terres rares. Office Parlementaire d'Evaluation des Choix Scientifiques et Technologiques, $n^{\circ} 617$ tome I (2015-2016).

[27] Hollander A and Lasserre P (1988) Monopoly and the preemption of competitive recycling. International Journal of Industrial Organization, 6, 489-497.

[28] Ichihara M and Harding A (1995) Human rights, the environment and radioactive waste: A study of the Asian rare earth case in Malaysia. Review of European, Comparative and International Environmental Law 4(1), 1-14.

[29] Kingsnorth DJ (2012) The global rare earths industry: A delicate balancing act. Presented at Deutsche Rohstoffagentur, 16th April 2012, Berlin, Germany. Available at: http://www.deutscherohstoffagentur.de/DERA/DE/Downloads/RD_kingsnorth_2012.pdf?_ blob $=$ publicationFile\&v $=2$

[30] Levin D (1985) Taxation within Cournot oligopoly. Journal of Public Economics $27,281-290$.

[31] Mankiw NG and Whinston MD (1986) Free entry and social inefficiency. Rand Journal of Economics 17(1), 48-58.

[32] Martin RE (1982) Monopoly power and the recycling of raw materials. The Journal of Industrial Economics 30(4), 405-419.

[33] Massari S and Ruberti M (2013) Rare earth elements as critical raw materials: Focus on international markets and future strategies. Resource Policy 38, 36-343. 
[34] Muller M, Schweizer D and Seiler V (2016) Wealth effects of rare earth prices and China's rare earth elements policy. Journal of Business Ethics 138, 627-648.

[35] OCDE (2015) Rare earth elements factsheet in Material Resources, Productivity and the Environment, OECD Editions, Paris.

[36] Packey DJ and Kingsnorth D (2016) The impact of unregulated ionic clay rare earth mining in China. Resources Policy, 48,

[37] Schüler D, Buchert M, Liu R, Dittrich S and Merz C (2011) Study on rare earths and their recycling. Final Report for the Greens/EFA Group in the European Parliament, Öko-Institut e.V.

[38] Seyhan D, Weikard HP and Ierland EV (2012) An economic model of longterm phosphorus extraction and recycling. Resources, Conservation and Recycling, 61, 103-108.

[39] Simpson RD (1995) Optimal pollution taxation in a Cournot duopoly. Environmental and Resource Economics 6, 359-369.

[40] Suslow VY (1986) Estimating monopoly behavior with competitive recycling: an application to Alcoa. The Rand Journal of Economics 17(3), 389-403.

[41] Swan PL (1980) Alcoa: The influence of recycling on monopoly power. Journal of Political Economy, 88(1), 76-99.

[42] US EPA (2012) Rare earth elements: a review of production, processing, recycling, and associated environmental issues. EPA-600-R-12-572, August 2012.

[43] US Geological Survey (2016) Mineral commodity summaries 2016, U.S. Geological Survey, 202. http://dx.doi.org/10.3133/70140094. 
[44] Weikard HP and Seyhan D (2009) Distribution of phosphorus resources between rich and poor countries: the effect of recycling. Ecological Economics 68, 1749-1755.

[45] Wübbeke J (2013) Rare earth elements in China: policies and narratives of reinventing an industry. Resources Policy 38, 384-394.

[46] Yang X, Zhang J and Fang X (2014) Rare earth element recycling from waste nickel-metal hydride batteries. Journal of Hazardous Materials 279, 384-388.

[47] Yokoo H and T Kinnaman (2013) Global Reuse and optimal waste policy. Environment and Development Economics 18(5), 595-614. 


\section{Appendix}

\section{APPENDIX A: The no-binding case}

\section{A1: The first-best}

\section{Concavity of the program}

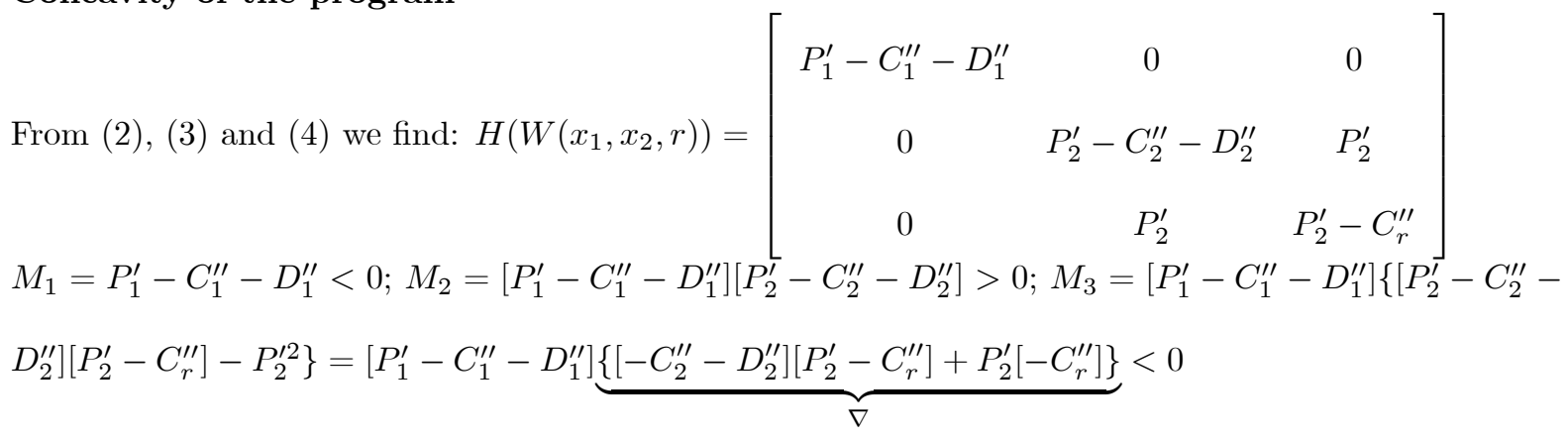

Effect of a change in $c_{s}$

$x_{1}^{* n c}\left(c_{s}\right)$ solves $P_{1}\left(x_{1}^{* n c}\right)-C_{1}^{\prime}\left(x_{1}^{* n c}\right)-2 \alpha c_{s}-D^{\prime}\left(x_{1}^{* n c}\right)=0$. We set $F\left(x_{1}, c_{s}\right)=P_{1}\left(x_{1}\right)-C_{1}^{\prime}\left(x_{1}\right)-2 \alpha c_{s}-$

$D^{\prime}\left(x_{1}\right)$. We apply the Implicit Function Theorem, and we find: $\frac{\partial x_{1}^{* n c}}{\partial c_{s}}=-\frac{\partial F\left(x_{1}, c_{s}\right) / \partial c_{s}}{\partial F\left(x_{1}, c_{s}\right) / \partial x_{1}}=-\frac{-2 \alpha}{M_{1}}<0$

$x_{2}^{* n c}\left(c_{s}\right)$ and $r^{* n c}\left(c_{s}\right)$ solve: $\left\{\begin{array}{l}P_{2}\left(x_{2}^{* n c}\left(c_{s}\right)+r^{* n c}\left(c_{s}\right)\right)-C_{2}^{\prime}\left(x_{2}^{* n c}\left(c_{s}\right)\right)-\alpha c_{s}-D_{2}^{\prime}\left(x_{2}^{* n c}\left(c_{s}\right)\right)=0 \\ P_{2}\left(x_{2}^{* n c}\left(c_{s}\right)+r^{* n c}\left(c_{s}\right)\right)-C_{r}^{\prime}\left(r^{* n c}\left(c_{s}\right)\right)=0\end{array}\right.$

If we differentiate this system with respect to $c_{s}$, we obtain after simplification:

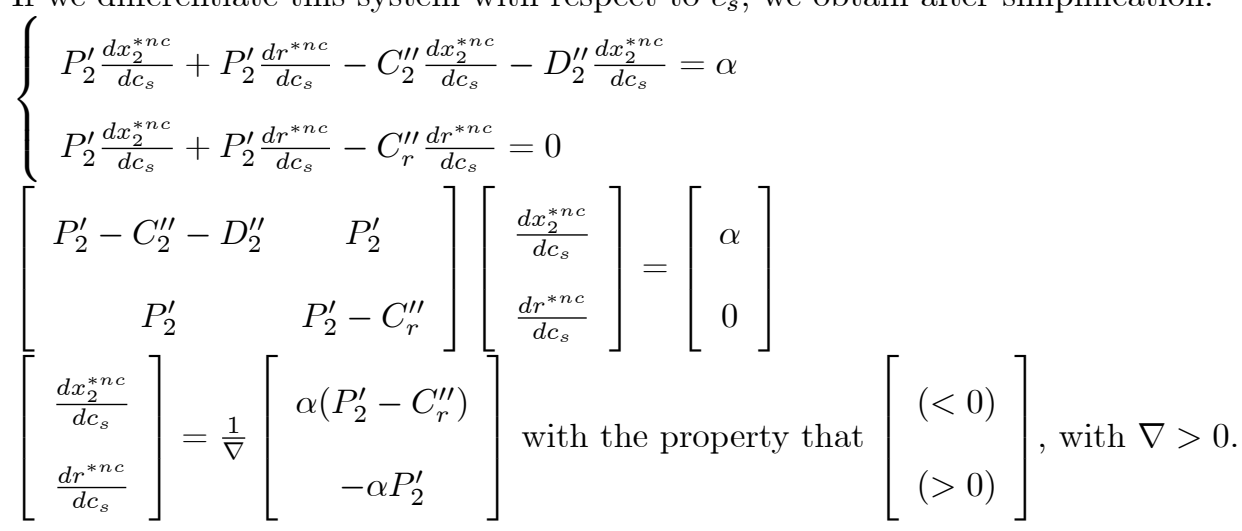

\section{A2: The recycling activity}

\section{Stability of the equilibrium}

As we have $\pi_{x_{2} x_{2}}^{e}=2 P_{2}^{\prime}+P_{2}^{\prime \prime} x_{2}-C_{2}^{\prime \prime}<0 ; \pi_{x_{2} r}^{e}=P_{2}^{\prime}+P_{2}^{\prime \prime} x_{2}<0 ; \pi_{r r}^{r}=2 P_{2}^{\prime}+P_{2}^{\prime \prime} r-C_{r}^{\prime \prime}<0$; $\pi_{r x_{2}}^{r}=P_{2}^{\prime}+P_{2}^{\prime \prime} r<0$. We find: $\pi_{x_{2} x_{2}}^{e}<\pi_{x_{2} r}^{e}<0$ and $\pi_{r r}^{r}<\pi_{x_{2} r}^{r}<0$, so $\Delta=\pi_{x_{2} x_{2}}^{e} \pi_{r r}^{r}-\pi_{x_{2} r}^{r} \pi_{r x_{2}}^{e}>0$. 
As $\pi_{x_{2} x_{2}}^{e}<0, \pi_{r r}^{r}<0$ and $\Delta>0$, the Gale-Nikaido condition is satisfied, meaning global uniqueness of the Cournot equilibrium. $\Delta>0$ is also the Routh-Hurwitz condition for reaction function stability. As $\pi_{x_{2} r}^{e}<0$ and $\pi_{r x_{2}}^{r}<0$, the quantity $x_{2}$ and $r$ are strategic substitutes.

\section{Effect of a change in $c_{s}$}

From (16), $x_{1}^{n c}\left(c_{s}\right)$ solves $P_{1}\left(x_{1}^{n c}\right)+P_{1}^{\prime}\left(x_{1}^{n c}\right) x_{1}^{n c}-C_{1}^{\prime}\left(x_{1}^{n c}\right)-2 \alpha c_{s}=0$. We set: $F\left(x_{1}, c_{s}\right)=\pi_{x_{1}}=$ $P_{1}\left(x_{1}\right)+P_{1}^{\prime}\left(x_{1}\right) x_{1}-C_{1}^{\prime}\left(x_{1}\right)-2 \alpha c_{s}$. We apply the Implicit Function Theorem, and we find: $\frac{\partial x_{1}^{n c}}{\partial c_{s}}=$ $-\frac{\partial F\left(x_{1}, c_{s}\right) / \partial c_{s}}{\partial F\left(x_{1}, c_{s}\right) / \partial x_{1}}=-\frac{-2 \alpha}{2 P_{1}^{\prime}+P_{1}^{\prime \prime} x_{1}-C_{1}^{\prime \prime}}=-\frac{-2 \alpha}{\pi_{x_{1} x_{1}}}<0$.

$x_{2}^{n c}\left(c_{s}\right)$ and $r^{n c}\left(c_{s}\right)$ solve:
$\left\{\begin{array}{c}P_{2}\left(x_{2}^{n c}\left(c_{s}\right)+r^{n c}\left(c_{s}\right)\right)+P_{2}^{\prime}\left(x_{2}^{n c}\left(c_{s}\right)+r^{n c}\left(c_{s}\right)\right) x_{2}^{n c}\left(c_{s}\right)-C_{2}^{\prime}\left(x_{2}^{n c}\left(c_{s}\right)\right)=\alpha c_{s} \\ P_{2}\left(x_{2}^{n c}\left(c_{s}\right)+r^{n c}\left(c_{s}\right)\right)+P_{2}^{\prime}\left(x_{2}^{n c}\left(c_{s}\right)+r^{n c}\left(c_{s}\right)\right) r^{n c}\left(c_{s}\right)-C_{r}^{\prime}\left(r^{n c}\left(c_{s}\right)\right)=0\end{array}\right.$
If we differentiate this system with respect to $c_{s}$, we obtain after simplification:
$\left\{\begin{array}{c}\frac{d x_{2}^{n c}}{d c_{s}}\left[2 P_{2}^{\prime}+P_{2}^{\prime \prime} x_{2}^{n c}-C_{2}^{\prime \prime}\right]+\frac{d r^{n c}}{d c_{s}}\left[P_{2}^{\prime}+P_{2}^{\prime \prime} x_{2}^{n c}\right]=\alpha \\ \frac{d x_{2}^{n c}}{d c_{s}}\left[P_{2}^{\prime}+P_{2}^{\prime \prime} r^{n c}\right]+\frac{d r^{n c}}{d c_{s}}\left[2 P_{2}^{\prime}+P_{2}^{\prime \prime} r^{n c}-C_{r}^{\prime \prime}\right]=0\end{array}\right.$
$\left\{\begin{array}{c}\frac{d x_{2}^{n c}}{d c_{s}}\left[\pi_{x_{2} x_{2}}^{e}\right]+\frac{d r^{n c}}{d c_{s}}\left[\pi_{x_{2} r}^{e}\right]=\alpha \\ \frac{d x_{2}^{n c}}{d c_{s}}\left[\pi_{r x_{2}}^{r}\right]+\frac{d r^{n c}}{d c_{s}}\left[\pi_{r r}^{r}\right]=0 \\ \left.\begin{array}{c}\frac{d x_{2}^{n c}}{d c_{s}} \\ \frac{d r^{n c}}{d c_{s}}\end{array}\right]=\frac{1}{\Delta}\left[\begin{array}{c}\pi_{r r}^{r} \\ -\pi_{x_{2} r}^{r}\end{array}\right] \pi_{r x_{2}}^{e} \\ {\left[\begin{array}{c}d x_{2}^{n c} \\ d c_{s} \\ \frac{d r^{n c}}{d c_{s}}\end{array}\right]=\frac{1}{\Delta}\left[\begin{array}{c}\alpha \\ \alpha \pi_{r r}^{r} \\ -\alpha \pi_{x_{2} r}^{r}\end{array}\right] \text { with the property that }\left[\begin{array}{l}(<0) \\ (>0)\end{array}\right] \text { with } \Delta=\pi_{x_{2} x_{2}}^{e} \pi_{r r}^{r}-\pi_{x_{2} r}^{r} \pi_{r x_{2}}^{e}>0 .}\end{array}\right.$

\section{A3: Exogenous environmental regulation}

\section{Effect of a change in $\tau_{1}$}

$x_{1}^{n c t}\left(c_{s}, \tau_{1}\right)$ solves: $P_{1}^{\prime}\left(x_{1}^{n c t}\left(c_{s}, \tau_{1}\right)\right) x_{1}^{n c t}\left(c_{s}, \tau_{1}\right)+P_{1}\left(x_{1}^{n c t}\left(c_{s}, \tau_{1}\right)\right)-C_{1}^{\prime}\left(x_{1}^{n c t}\left(c_{s}, \tau_{1}\right)\right)-2 \alpha c_{s}-\tau_{1}=0$. We set: $F\left(x_{1}, c_{s}, \tau_{1}\right)=P_{1}^{\prime}\left(x_{1}\right) x_{1}+P_{1}\left(x_{1}\right)-C_{1}^{\prime}\left(x_{1}\right)-2 \alpha c_{s}-\tau_{1}$. We apply the Implicit Function Theorem, and we find: $\frac{\partial x_{1}^{n c t}}{\partial \tau_{1}}=-\frac{\partial F\left(x_{1}, c_{s}, \tau_{1}\right) / \partial \tau_{1}}{\partial F\left(x_{1}, c_{s}, \tau_{1}\right) / \partial x_{1}}=-\frac{-1}{P_{1}^{\prime \prime} x_{1}+2 P_{1}^{\prime}-C_{1}^{\prime \prime}\left(x_{1}\right)}<0$

\section{Effect of a change in $\tau_{2}$}

$x_{2}^{n c t}\left(c_{s}, \tau_{2}\right)$ and $r^{n c t}\left(c_{s}, \tau_{2}\right)$ solve: 


$$
\left\{\begin{array}{l}
P_{2}^{\prime}\left(x_{2}^{n c t}\left(c_{s}, \tau_{2}\right)+r^{n c t}\left(c_{s}, \tau_{2}\right)\right) x_{2}^{n c t}\left(c_{s}, \tau_{2}\right)+P_{2}\left(x_{2}^{n c t}\left(c_{s}, \tau_{2}\right)+r^{n c t}\left(c_{s}, \tau_{2}\right)\right)-C_{2}^{\prime}\left(x_{2}^{n c t}\left(c_{s}, \tau_{2}\right)\right)-\alpha c_{s}-\tau_{2}=0 \\
P_{2}\left(x_{2}^{n c t}\left(c_{s}, \tau_{2}\right)+r^{n c t}\left(c_{s}, \tau_{2}\right)\right)+P_{2}^{\prime}\left(x_{2}^{n c t}\left(c_{s}, \tau_{2}\right)+r^{n c t}\left(c_{s}, \tau_{2}\right) r^{n c t}-C_{r}^{\prime}\left(r^{n c t}\left(c_{s}, \tau_{2}\right)\right)=0\right.
\end{array}\right.
$$

If we differentiate this system with respect to $\tau_{2}$, we obtain after simplification:

$$
\begin{aligned}
& \left\{\begin{array}{l}
\frac{d x_{2}^{n c t}}{d \tau_{2}}\left[2 P_{2}^{\prime}+P_{2}^{\prime \prime} x_{2}^{n c t}-C_{2}^{\prime \prime}\right]+\frac{d r^{n c t}}{d \tau_{2}}\left[P_{2}^{\prime}+P_{2}^{\prime \prime} x_{2}^{n c t}\right]=1 \\
\frac{d x_{2}^{n c t}}{d \tau_{2}}\left[P_{2}^{\prime}+P_{2}^{\prime \prime} r^{n c t}\right]+\frac{d r^{n c t}}{d \tau_{2}}\left[2 P_{2}^{\prime}+P_{2}^{\prime \prime} r^{n c t}-C_{r}^{\prime \prime}\right]=0 \\
\frac{d x_{2}^{n c t}}{d \tau_{2}}\left[\pi_{x_{2} x_{2}}^{e}\right]+\frac{d r^{n c t}}{d \tau_{2}}\left[\pi_{x_{2} r}^{e}\right]=1 \\
\frac{d x_{2}^{n c t}}{d \tau_{2}}\left[\pi_{r x_{2}}^{r}\right]+\frac{d r^{n c t}}{d \tau_{2}}\left[\pi_{r r}^{r}\right]=0
\end{array}\right. \\
& {\left[\begin{array}{c}
\frac{d x_{2}^{n c t}}{d \tau_{2}} \\
\frac{d r^{n c t}}{d \tau_{2}}
\end{array}\right]=\frac{1}{\Delta}\left[\begin{array}{cc}
\pi_{r r}^{r} & -\pi_{r x_{2}}^{e} \\
-\pi_{x_{2} r}^{r} & \pi_{x_{2} x_{2}}^{e}
\end{array}\right]\left[\begin{array}{l}
1 \\
0
\end{array}\right]} \\
& {\left[\begin{array}{c}
\frac{d x_{2}^{n c t}}{d \tau_{2}} \\
\frac{d r^{n c t}}{d \tau_{2}}
\end{array}\right]=\frac{1}{\Delta}\left[\begin{array}{c}
\pi_{r r}^{r} \\
-\pi_{x_{2} r}^{r}
\end{array}\right] \text { with the property that }\left[\begin{array}{l}
(<0) \\
(>0)
\end{array}\right] \text { with } \Delta>0 .}
\end{aligned}
$$

APPENDIX B: The binding case. We assume $P^{\prime \prime}=0$ and $C^{\prime \prime \prime}=0$.

\section{B1: The first-best}

\section{Concavity of the program}

From (10) we find: $H\left(W\left(x_{1}, x_{2}, r\right)\right)=\left[\begin{array}{cc}P_{1}^{\prime}-C_{1}^{\prime \prime}-D_{1}^{\prime \prime}+k^{2} P_{2}^{\prime}-k^{2} C_{r}^{\prime \prime} & k P_{2}^{\prime} \\ k P_{2}^{\prime} & P_{2}^{\prime}-C_{2}^{\prime \prime}-D_{2}^{\prime \prime}\end{array}\right]$

$W_{x_{1} x_{1}}=\left[P_{1}^{\prime}-C_{1}^{\prime \prime}-D_{1}^{\prime \prime}+k^{2} P_{2}^{\prime}-k^{2} C_{r}^{\prime \prime}\right]<0 ; W_{x_{1} x_{2}}=k P_{2}^{\prime}=W_{x_{2} x_{1}}<0 ; W_{x_{2} x_{2}}=P_{2}^{\prime}-C_{2}^{\prime \prime}-D_{2}^{\prime \prime}<0$.

$\operatorname{Det} H=\Psi=\left[P_{1}^{\prime}-C_{1}^{\prime \prime}-D_{1}^{\prime \prime}+k^{2} P_{2}^{\prime}-k^{2} C_{r}^{\prime \prime}\right]\left[P_{2}^{\prime}-C_{2}^{\prime \prime}-D_{2}^{\prime \prime}\right]-\left[k P_{2}^{\prime}\right]^{2}=\left[P_{1}^{\prime}-C_{1}^{\prime \prime}-D_{1}^{\prime \prime}-k^{2} C_{r}^{\prime \prime}\right]\left[P_{2}^{\prime}-C_{2}^{\prime \prime}-\right.$ $\left.D_{2}^{\prime \prime}\right]+k^{2} P_{2}^{\prime}\left[-C_{2}^{\prime \prime}-D_{2}^{\prime \prime}\right]>0$.

\section{Effect of a change in $\mathbf{c}_{s}$}

$x_{1}^{* c}\left(c_{s}\right)$ and $x_{2}^{* c}\left(c_{s}\right)$ solve:
$P_{1}\left(x_{1}^{* c}\left(c_{s}\right)\right)-C_{1}^{\prime}\left(x_{1}^{* c}\left(c_{s}\right)\right)-2 \alpha c_{s}-D_{1}^{\prime}\left(x_{1}^{* c}\left(c_{s}\right)\right)+k\left[P_{2}\left(x_{2}^{* c}\left(c_{s}\right)+k x_{1}^{* c}\left(c_{s}\right)\right)-C_{r}^{\prime}\left(k x_{1}^{* c}\left(c_{s}\right)\right)\right]=0$
$P_{2}\left(x_{2}^{* c}\left(c_{s}\right)+k x_{1}^{* c}\left(c_{s}\right)\right)-C_{2}^{\prime}\left(x_{2}^{* c}\left(c_{s}\right)\right)-\alpha c_{s}-D_{2}^{\prime}\left(x_{2}^{* c}\left(c_{s}\right)\right)=0$

If we differentiate this system with respect to $C_{s}$, we obtain after simplification:

$\left\{\begin{array}{l}P_{1}^{\prime} \frac{d x_{1}^{* c}}{d c_{s}}-C_{1}^{\prime \prime} \frac{d x_{1}^{* c}}{d c_{s}}-D_{1}^{\prime \prime} \frac{d x_{1}^{* c}}{d c_{s}}+k\left[P_{2}^{\prime}\left[\frac{d x_{2}^{* c}}{d c_{s}}+k \frac{d x_{1}^{* c}}{d c_{s}}\right]-k^{2} C_{r}^{\prime \prime} \frac{d x_{1}^{* c}}{d c_{s}}\right]=2 \alpha \\ P_{2}^{\prime}\left[\frac{d x_{2}^{* c}}{d c_{s}}+k \frac{d x_{1}^{* c}}{d c_{s}}\right]-C_{2}^{\prime \prime} \frac{d x_{2}^{* c}}{d c_{s}}-D_{2}^{\prime \prime} \frac{d x_{2}^{* c}}{d c_{s}}=\alpha\end{array}\right.$ 


$$
\begin{aligned}
& \left\{\begin{array}{c}
\frac{d x_{1}^{* c}}{d c_{s}}\left[P_{1}^{\prime}-C_{1}^{\prime \prime}-D_{1}^{\prime \prime}+k^{2} P_{2}^{\prime}-k^{2} C_{r}^{\prime \prime}\right]+\frac{d x_{2}^{* c}}{d c_{s}} k P_{2}^{\prime}=2 \alpha \\
\left.\frac{d x_{2}^{* c}}{d c_{s}}\left[P_{2}^{\prime}-C_{2}^{\prime \prime}-D_{2}^{\prime \prime}\right]+P_{2}^{\prime} k \frac{d x_{1}^{* c}}{d c_{s}}\right]=\alpha
\end{array}\right]\left[\begin{array}{c}
2 \alpha \\
\frac{d x_{1}^{* c}}{d c_{s}} \\
\frac{d x_{2}^{* c}}{d c_{s}}
\end{array}\right]=\frac{1}{\Psi}\left[\begin{array}{cc}
P_{2}^{\prime}-C_{2}^{\prime \prime}-D_{2}^{\prime \prime} & -k P_{2}^{\prime} \\
-k P_{2}^{\prime} & P_{1}^{\prime}-C_{1}^{\prime \prime}-D_{1}^{\prime \prime}+k^{2} P_{2}^{\prime}-k^{2} C_{r}^{\prime \prime}
\end{array}\right]\left[\begin{array}{c}
\alpha
\end{array}\right] \\
& \text { with } \Psi>0, \text { we obtain: }\left\{\begin{array}{l}
\left.\frac{d x_{1}^{* c}}{d c_{s}}=\frac{\alpha}{\Psi}\left\{P_{2}^{\prime}(2-k)-2 C_{2}^{\prime \prime}-2 D^{\prime \prime}\right]\right\}<0 \\
\frac{d x_{2}^{* c}}{d c_{s}}=\frac{\alpha}{\Psi}\left\{P^{\prime}\left[k^{2}-2 k+1\right]-C_{1}^{\prime \prime}-D_{1}^{\prime \prime}-k^{2} C_{r}^{\prime \prime}\right\}<0
\end{array}\right.
\end{aligned}
$$

\section{B2: The recycling activity}

\section{Variation of $x_{2}^{c}$ with respect to $x_{1:}^{c}$}

From (15), we note $F\left(x_{1}, x_{2}\right)=P_{2}\left(x_{2}+k x_{1}\right)+P_{2}^{\prime}\left(x_{2}+k x_{1}\right) x_{2}-C_{2}^{\prime}\left(x_{2}\right)-\alpha c_{s}=0$. So $\frac{\partial x_{2}^{c}}{\partial x_{1}^{c}}=$ $-\frac{\partial F\left(x_{2}, x_{1}\right) / \partial x_{1}}{\partial F\left(x_{2}, x_{1}\right) / \partial x_{2}}=-\frac{k P_{2}^{\prime}}{2 P_{2}^{\prime}-C_{2}^{\prime \prime}}<0$.

\section{Concavity of the profit in the first stage:}

From (17), $\Pi_{x_{1}}^{e}=P_{1}\left(x_{1}^{c}\right)+P_{1}^{\prime}\left(x_{1}^{c}\right) x_{1}^{c}-C_{1}^{\prime}\left(x_{1}^{c}\right)-2 \alpha c_{s}+\frac{d x_{2}^{c}}{d x_{1}^{c}}\left[P_{2}\left(x_{2}^{c}\left(x_{1}^{c}\right)+k x_{1}^{c}\right)+P_{2}^{\prime}\left(x_{2}^{c}\left(x_{1}^{c}\right)+k x_{1}^{c}\right) x_{2}^{c}\left(x_{1}^{c}\right)-\right.$

$\left.C_{2}^{\prime}\left(x_{2}^{c}\left(x_{1}^{c}\right)\right)-\alpha c_{s}\right]+k P_{2}^{\prime}\left(x_{2}^{c}\left(x_{1}^{c}\right)+k x_{1}^{c}\right) x_{2}^{c}\left(x_{1}^{c}\right)$

$\Pi_{x_{1} x_{1}}^{e}=2 P_{1}^{\prime}-C_{1}^{\prime \prime}+\frac{d x_{2}^{c}}{d x_{1}^{c}}\left\{\frac{d x_{2}^{c}}{d x_{1}^{c}}\left[2 P_{2}^{\prime}-C_{2}^{\prime \prime}\right]+2 k P_{2}^{\prime}\right\}=\frac{1}{\left[2 P_{2}^{\prime}-C_{2}^{\prime \prime \prime}\right]}\left\{\left[2 P_{1}^{\prime}-C_{1}^{\prime \prime}\right]\left[2 P_{2}^{\prime}-C_{2}^{\prime \prime}\right]-\left[k P_{2}^{\prime}\right]^{2}\right\}$

$=\frac{1}{\left[2 P_{2}^{\prime}-C_{2}^{\prime \prime}\right]}\{\underbrace{\left[P^{\prime}\right]^{2}(4-k)-C_{1}^{\prime \prime}\left[2 P_{2}^{\prime}-C_{2}^{\prime \prime}\right]-2 P_{1}^{\prime} C_{2}^{\prime \prime}}_{\Theta>0}\}<0$.

\section{Effect of a change in $c_{s}$}

At the equilibrium, $x_{1}^{c}\left(c_{s}\right)$ and $x_{2}^{c}\left(c_{s}\right)$ solve:

$$
\left\{\begin{array}{l}
P_{1}\left(x_{1}^{c}\right)+P_{1}^{\prime}\left(x_{1}^{c}\right) x_{1}^{c}-C_{1}^{\prime}\left(x_{1}^{c}\right)-2 \alpha c_{s}+\frac{d x_{2}^{c}}{d x_{1}^{c}}\left[P_{2}\left(x_{2}^{c}+k x_{1}^{c}\right)+P_{2}^{\prime}\left(x_{2}^{c}+k x_{1}^{c}\right) x_{2}^{c}-C_{2}^{\prime}\left(x_{2}^{c}\right)-\alpha c_{s}\right]+k P_{2}^{\prime}\left(x_{2}^{c}+k x_{1}^{c}\right) x_{2}^{c}=0 \\
P_{2}\left(x_{2}^{c}+k x_{1}^{c}\right)+P_{2}^{\prime}\left(x_{2}^{c}+k x_{1}^{c}\right) x_{2}^{c}-C_{2}^{\prime}\left(x_{2}^{c}\right)-\alpha c_{s}=0
\end{array}\right.
$$

If we differentiate this system with respect to $c_{s}$, we obtain:

$$
\begin{aligned}
& \left\{\begin{array}{c}
\frac{d x_{1}^{c}}{d c_{s}}\left[2 P_{1}^{\prime}+P_{1}^{\prime \prime} x_{1}^{c}-C_{1}^{\prime \prime}+\frac{d x_{2}^{c}\left(x_{1}^{c}\right)}{d x_{1}^{c}}\left[P_{2}^{\prime} k+k P_{2}^{\prime \prime} x_{2}^{c}+k^{2} P_{2}^{\prime \prime} x_{2}^{c}\right]+\frac{d x_{2}^{c}}{d c_{s}}\left[k P_{2}^{\prime \prime} x_{2}^{c}+k P_{2}^{\prime}+\frac{d x_{2}^{c}\left(x_{1}^{c}\right)}{d x_{1}^{c}}\left(2 P_{2}^{\prime}-C_{2}^{\prime \prime}+P_{2}^{\prime \prime} x_{2}\right)\right]\right. \\
\frac{d x_{1}^{c}}{d c_{s}}\left[k P_{2}^{\prime}+k P_{2}^{\prime \prime} x_{2}^{c}\right]+\frac{d x_{2}^{c}}{d c_{s}}\left[2 P_{2}^{\prime}+P_{2}^{\prime \prime} x_{2}^{c}-C_{2}^{\prime \prime}\right]=\alpha \\
{\left[\begin{array}{c}
\frac{d x_{1}^{c}}{d c_{s}} \\
\frac{d x_{2}^{c}}{d c_{s}}
\end{array}\right]=\frac{1}{\Phi}\left[\begin{array}{cc}
2 P_{2}^{\prime}-C_{2}^{\prime \prime} & -\left[k P_{2}^{\prime}+\frac{d x_{2}^{c}\left(x_{1}^{c}\right)}{d x_{1}^{c}}\left(2 P_{2}^{\prime}-C_{2}^{\prime \prime}\right)\right] \\
-\left[k P_{2}^{\prime}\right] & 2 P_{1}^{\prime}-C_{1}^{\prime \prime}+\frac{d x_{2}^{c}\left(x_{1}^{c}\right)}{d x_{1}^{c}}\left[P_{2}^{\prime} k\right]
\end{array}\right]\left[\begin{array}{c}
\alpha\left[2+\frac{d x_{2}^{c}\left(x_{1}^{c}\right)}{d x_{1}^{c}}\right] \\
\alpha
\end{array}\right]}
\end{array}\right. \\
& \text { With } \Theta=\left[2 P_{1}^{\prime}-C_{1}^{\prime \prime}\right]\left[2 P_{2}^{\prime}-C_{2}^{\prime}\right]-\left[k P_{2}^{\prime}\right]^{2}>0, \text { we find: }\left\{\begin{array}{c}
\frac{d x_{1}^{c}}{d c_{s}}=\frac{1}{\Delta}\left[\alpha P_{2}^{\prime}[4-k]-2 \alpha C_{2}^{\prime \prime}\right]<0 \\
\frac{d x_{2}^{c}}{d c_{s}}=\frac{\alpha}{\Delta}\left[2 P^{\prime}(1-k)-C_{1}^{\prime \prime}\right]<0
\end{array}\right.
\end{aligned}
$$




\section{B3: Exogenous environmental regulation}

Effect of a change in $\tau_{1}$ and $\tau_{2}$

$x_{1}^{c t}\left(c_{s}, \tau_{1}, \tau_{2}\right)$ and $x_{2}^{c t}\left(c_{s}, \tau_{1}, \tau_{2}\right)$ solve:

$\left\{\begin{array}{c}P_{1}\left(x_{1}^{c t}\left(c_{s}, \tau_{1}, \tau_{2}\right)\right)+P_{1}^{\prime}\left(x_{1}^{c t}\left(c_{s}, \tau_{1}, \tau_{2}\right)\right) x_{1}^{c t}\left(c_{s}, \tau_{1}, \tau_{2}\right)-C_{1}^{\prime}\left(x_{1}^{c t}\left(c_{s}, \tau_{1}, \tau_{2}\right)\right)-2 \alpha c_{s}-\tau_{1}+ \\ \frac{d x_{2}^{c}}{d x_{1}^{c}}\left[P_{2}\left(x_{2}^{c t}\left(c_{s}, \tau_{1}, \tau_{2}\right)+k x_{1}^{c t}\left(c_{s}, \tau_{1}, \tau_{2}\right)\right)+P_{2}^{\prime}\left(x_{2}^{c t}\left(c_{s}, \tau_{1}, \tau_{2}\right)+k x_{1}^{c t}\left(c_{s}, \tau_{1}, \tau_{2}\right)\right) x_{2}^{c t}\left(c_{s}, \tau_{1}, \tau_{2}\right)\right. \\ \left.-C_{2}^{\prime}\left(x_{2}^{c t}\left(c_{s}, \tau_{1}, \tau_{2}\right)\right)-\alpha c_{s}-\tau_{2}\right]+k P_{2}^{\prime}\left(x_{2}^{c t}\left(c_{s}, \tau_{1}, \tau_{2}\right)+k x_{1}^{c t}\left(c_{s}, \tau_{1}, \tau_{2}\right)\right) x_{2}^{c t}\left(c_{s}, \tau_{1}, \tau_{2}\right)=0 \\ P_{2}\left(x_{2}^{c t}\left(c_{s}, \tau_{1}, \tau_{2}\right)+k x_{1}^{c t}\left(c_{s}, \tau_{1}, \tau_{2}\right)\right)+P_{2}^{\prime}\left(x_{2}^{c t}\left(c_{s}, \tau_{1}, \tau_{2}\right)+k x_{1}^{c t}\left(c_{s}, \tau_{1}, \tau_{2}\right)\right) x_{2} \\ -C_{2}^{\prime}\left(x_{2}^{c t}\left(c_{s}, \tau_{1}, \tau_{2}\right)\right)-\alpha C_{s}-\tau_{2}=0\end{array}\right.$

If we differentiate this system with respect to $\tau_{1}$ and $\tau_{2}$, we obtain after simplification:

$$
\begin{aligned}
& \int 2 P_{1}^{\prime} \frac{d x_{1}^{c t}}{d \tau_{1}}-C_{1}^{\prime \prime} \frac{d x_{1}^{c t}}{d \tau_{1}}+\frac{d x_{2}^{c t}}{d x_{1}^{c t}}\left\{P_{2}^{\prime}\left[\frac{d x_{2}^{c t}}{d \tau_{1}}+k \frac{d x_{1}^{c t}}{d \tau_{1}}\right]+P_{2}^{\prime} \frac{d x_{2}^{c t}}{d \tau_{1}}-C_{2}^{\prime \prime} \frac{d x_{2}^{c t}}{d \tau_{1}}\right\}+k P_{2}^{\prime} \frac{d x_{2}^{c t}}{d \tau_{1}}=1 \\
& 2 P_{1}^{\prime} \frac{d x_{1}^{c t}}{d \tau_{2}}-C_{1}^{\prime \prime} \frac{d x_{1}^{c t}}{d \tau_{2}}+\frac{d x_{2}^{c t}}{d x_{1}^{c t}}\left\{P_{2}^{\prime}\left[\frac{d x_{2}^{c t}}{d \tau_{2}}+k \frac{d x_{1}^{c t}}{d \tau_{2}}\right]+P_{2}^{\prime} \frac{d x_{2}^{c t}}{d \tau_{2}}-C_{2}^{\prime \prime} \frac{d x_{2}^{c t}}{d \tau_{2}}\right\}+k P_{2}^{\prime} \frac{d x_{2}^{c t}}{d \tau_{2}}=\frac{d x_{2}^{c t}}{d x_{1}^{c t}} \\
& P_{2}^{\prime}\left[\frac{d x_{2}^{c t}}{d \tau_{1}}+k \frac{d x_{1}^{c t}}{d \tau_{1}}\right]+P_{2}^{\prime} \frac{d x_{2}^{c t}}{d \tau_{1}}-C_{2}^{\prime \prime} \frac{d x_{2}^{c t}}{d \tau_{1}}=0 \\
& P_{2}^{\prime}\left[\frac{d x_{2}^{c t}}{d \tau_{2}}+k \frac{d x_{1}^{c t}}{d \tau_{2}}\right]+P_{2}^{\prime} \frac{d x_{2}^{c t}}{d \tau_{2}}-C_{2}^{\prime \prime} \frac{d x_{2}^{c t}}{d \tau_{2}}=1 \\
& {\left[\begin{array}{c}
\frac{d x_{1}^{c t}}{d \tau_{1}} \\
\frac{d x_{2}^{c t}}{d \tau_{1}} \\
\frac{d x_{1}^{c t}}{d \tau_{2}} \\
\frac{d x_{2}^{c t}}{d \tau_{2}}
\end{array}\right]=\left[\begin{array}{cccc}
A & 0 & 0 & 0 \\
0 & 0 & A & 0 \\
C & D & 0 & 0 \\
0 & 0 & C & D
\end{array}\right]^{-1}\left[\begin{array}{c}
1 \\
\frac{d x_{2}^{c t}}{d x_{1}^{c t}} \\
0 \\
1
\end{array}\right] \text {, }}
\end{aligned}
$$

with: $A=2 P_{1}^{\prime}-C_{1}^{\prime \prime}-\frac{\left(k P_{2}^{\prime}\right)^{2}}{2 P_{2}^{\prime}-C_{2}^{\prime \prime}}<0 ; B=-\frac{k P_{2}^{\prime}}{2 P_{2}^{\prime}-C_{2}^{\prime \prime}}\left[2 P_{2}^{\prime}-C_{2}^{\prime \prime}\right]+k P_{2}^{\prime}=0 ; C=P_{2}^{\prime} k<0 ; D=2 P_{2}^{\prime}-C_{2}^{\prime \prime}<0$.

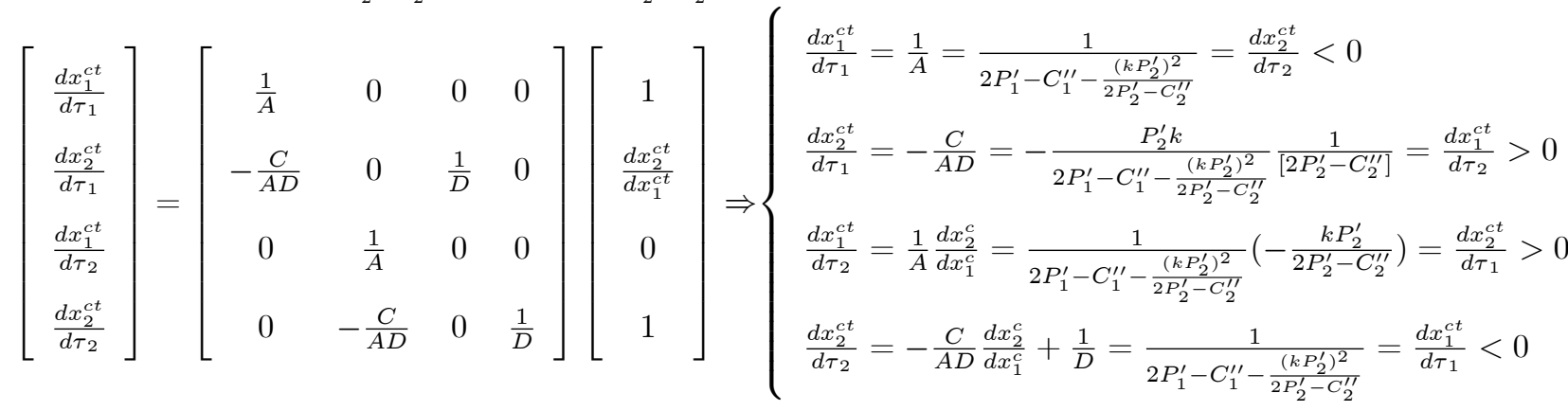

\section{Total variation of extracted quantities}

$d x_{i}^{c t}=\frac{\partial x_{i}^{c t}}{\partial \tau_{1}} d \tau_{1}+\frac{\partial x_{i}^{c t}}{\partial \tau_{2}} d \tau_{2} \lessgtr 0$ depending on $d \tau_{1}$ and $d \tau_{2}$. If $d \tau_{1}=d \tau_{2}=d \tau>0, d x_{i}=d \tau\left[\frac{\partial x_{i}^{c t}}{\partial \tau_{1}}+\frac{\partial x_{i}^{c t}}{\partial \tau_{2}}\right]=$ $d \tau\left[\frac{1}{2 P_{1}^{\prime}-C_{1}^{\prime \prime}-\frac{\left(k P_{2}^{\prime}\right)^{2}}{2 P_{2}^{\prime}-C_{2}^{\prime \prime}}}\right]\left[1-\frac{k P_{2}^{\prime}}{2 P_{2}^{\prime}-C_{2}^{\prime \prime}}\right]<0$. 